\title{
NSF weighs value of supercomputer centres
}

\begin{abstract}
Washington. An advisory panel is reviewing the rationale behind four supercomputer centres funded by the US National Science Foundation (NSF) as part of an overall look at the role of high-performance computing in science. A 14-member panel, meeting last week for the first time, discussed whether NSF should continue to pay for big, expensive mainframe machines at national centres in a world of cheap, powerful desktop workstations, high-speed communication networks and parallel processing. The group also will consider the appropriate relationship between NSF and other federal agencies with a greater investment in supercomputers.
\end{abstract}

The 14-member panel, appointed by NSF, is chaired by Lewis Branscomb of Harvard University and intends to meet several times before submitting a report in May to the National Science Board, which supervises the foundation's activities.

Last year, NSF spent $\$ 56$ million on the Cornell Theory Center at Cornell University, the National Center for Supercomputing Applications at the University of Illinois, the Pittsburgh Supercomputing Center at Carnegie Mellon University and the San Diego Supercomputer Center at the University of California, providing 56 per cent of their total budget. Formed in the mid-1980s, the centres are expected to be innovators, educators and proselytizers, finding new applications for supercomputers, attracting new users and helping existing ones make the most of high-performance machines. But there is now concern that the centres in some cases serve mostly as 'cycle shops' for a small group of researchers who need large

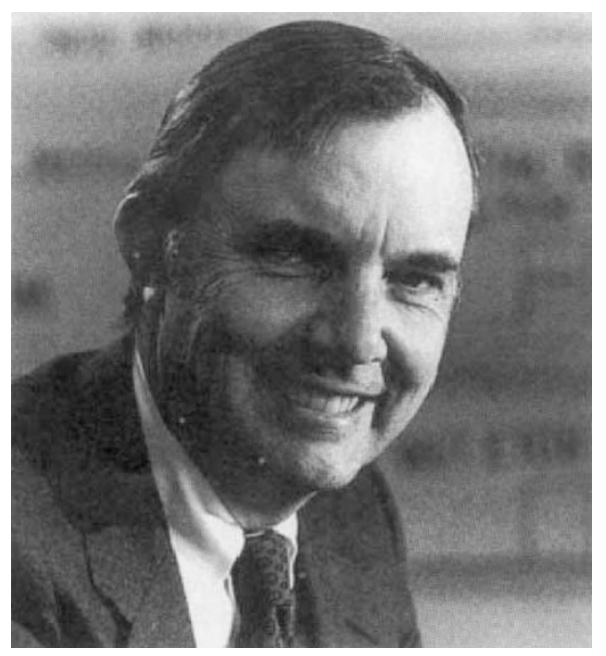

Branscomb looks at changing world.

amounts of supercomputer time, or cycles.

The panel will look at more than just the fate of the NSF centres, however. "We have to think about how the whole relationship between the world of science and the world of computing has changed", says Branscomb, a former chief scientist at IBM. The panel would like to anticipate high-end hardware and software that will be on the market in the next five years, as well as the uses to which they will be put.

Another question facing the panel is NSF's relationship to other public and private programmes. Federal agencies such as the Department of Defense, the National Aeronautics and Space Administration and the Department of Energy all spend more on supercomputers than does NSF and play a bigger part in the coordinated federal HighPerformance Computing and Communications initiative begun last year to accelerate US progress in the field. Vice President $\mathrm{Al}$ Gore is expected to lead a campaign by the Clinton administration to strengthen the High-Performance Computing Act of 1991, which Gore introduced, as part of its pledge to invest in an information 'infrastructure'.

The panel is seeking the advice of the computer industry and other government agencies who use supercomputers and scientists, including professional societies. It also expects to consult with other state-run and university-based supercomputing centres, several of which have capabilities matching those of the NSF-supported centres. The panel includes researchers who have used high-performance computing in their own scientific and mathematical work - "people who have a good knowledge of the technology", says Branscomb.

Tony Reichhardt

\section{Institute is centre of political war in ex-Soviet republic}

Moscow. An attempt by the newly independent Bashkortostan Republic to take over a research centre formerly operated by the Russian Academy of Sciences has dimmed prospects for researchers in the capital city of Ufa. A compromise has been struck to assuage the pride of local politicians, who formed a Bashkir Academy of Sciences as a way of asserting their independence from Russia, but many scientists have already left or begun to look for work outside the Ural Mountains region.

The problem started when the Bashkortostan Supreme Soviet decided to transfer authority for the Bashkir Scientific Centre, with its eight research institutes, to the newly formed Bashkir academy. But the academy is a purely national structure with little interest in fundamental research; three of its 14 institutes have nothing to do with science, and others are concerned with medicine, agriculture and other applied fields. The move was a blatant attempt to confiscate federal property, according to Henri Tolstikov, chairman of the Bashkir Scientific Centre, and was made without regard to its impact on science.

In response, Russia dispatched three vice premiers, including science minister Boris Saltykov, who strongly urged the Bashkortostan government to reconsider its decision. The discussions produced a compromise: the republic would drop its claim to the scientific centre if the Russian academy transferred control of the scientific centre from its Urals branch directly to the academy presidium.

Although this compromise is now in effect, there is concern that it will not hold. Tolstikov says that the ruling élite harbour nationalistic and anti-Russian feelings that could subvert the agreement and make it impossible for the Russian academy to exert control over the centre. Tolstikov has been branded an "enemy of the Bashkir people" for his refusal to go along with what he calls "the inflammation of sovereignties" spawned by the breakup of the Soviet empire.

In the meantime, the fate of academic science in the region hangs in the balance. Academician Nikolai Laverov, one of the members of the Russian delegation that negotiated the compromise, insists that any attempt to seize academy property must be stopped. "Otherwise", he says, "we will be forced to declare the destruction of science in Bashkir."

Vladimir Pokrovsky

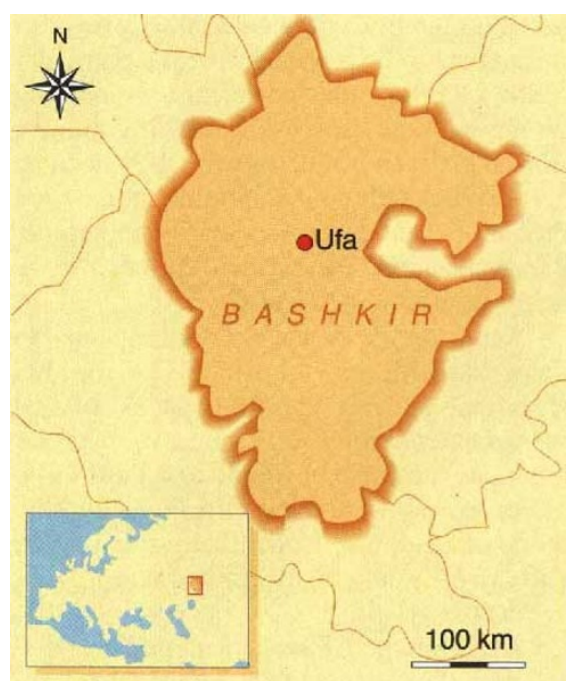

